\title{
Psychiatric aspects of Traumatic Brain Injury in professional sports
}

\section{CONCUSSION / DEPRESSION / NEUROLOGY}

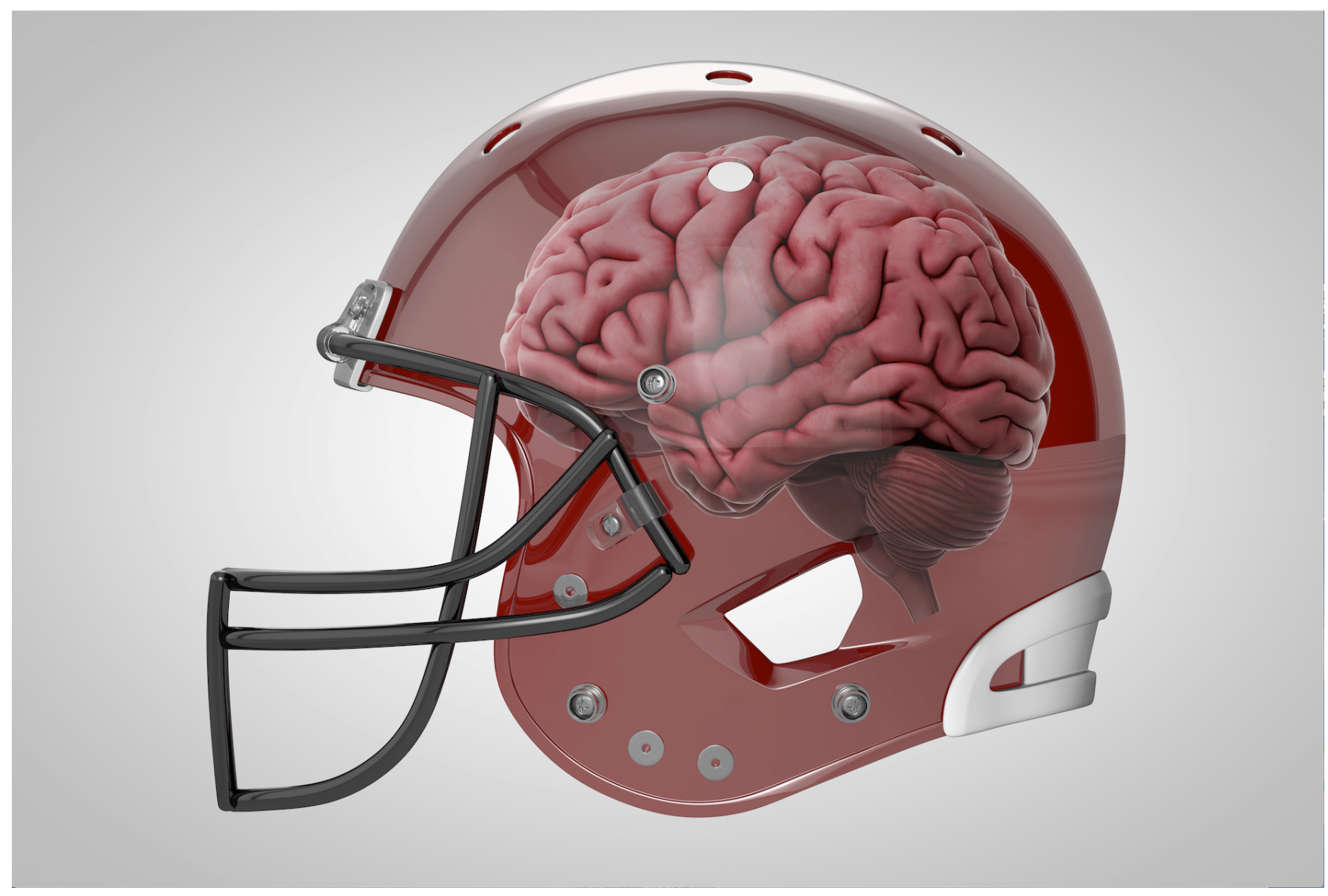

Deutschmann Markus ${ }^{1}$, Dewey Maryse ${ }^{2}$, Langer Martina ${ }^{1}$, Seifritz $\operatorname{Erich}^{1}$, Claussen Malte Christian ${ }^{1,2,3}$

${ }^{1}$ Department of Psychiatry, Psychotherapy and Psychosomatics, University Hospital of Psychiatry Zurich, Zurich, Switzerland

${ }^{2}$ Private Clinic Wyss AG, Münchenbuchsee, Switzerland

${ }^{3}$ Psychiatric Services Grisons, Chur, Switzerland

For nearly a century it has been hypothesized, that repetitive head trauma can lead to adverse neurological and psychiatric conditions [1]. Still, it took the discovery of Chronic Traumatic Encephalopathy (CTE) in a player of the National Football League to bring widespread public and scientific 
attention to this important topic on the intersection of neurology, psychiatry and sports medicine [2,3]. Traumatic Brain Injuries are a significant medical and socioeconomic burden that reaches far beyond professional sports, leading to the disability of millions worldwide [4,5,6]. An understanding of the psychiatric aspects of head trauma therefore is necessary among physicians to assure optimal medical care for these patients.

The terminology of Traumatic Brain Injury is complicated and in part contradicting. However, it is important to define an unanimous nomenclature in order to facilitate scientific and medical discourse. The term "head trauma" is very broad and can refer to a wide range of injuries from a broken nose to a cerebral haemorrhage. Therefore, to specify brain damage in the context of trauma, the term "Traumatic Brain Injury (TBI)" is used. TBI can be graded in "mild", "moderate" and "severe", based on the Glasgow Coma Scale and the degree of post-concussive amnesia and loss of consciousness [7,8]. Mild Traumatic Brain Injury (mTBI) is with $90 \%$ by far the most prevalent TBI and one of the most abundant neurological disorders $[9,10]$. The term "concussion" is often used interchangeably with "mTBI", especially in sports medicine. Yet the American Medical Society for Sports Medicine defines concussion as a "traumatically induced transient disturbance of brain function (...). Concussion is a subset of mild traumatic brain injury, (...) at the less severe end of the brain injury spectrum” [11].

mTBI patients may experience a variety of post-concussive symptoms, which can range from somatic symptoms (e.g. headache, dizziness, nausea), neurocognitive symptoms (e.g. disorientation), emotional symptoms (e.g. irritability, anxiety) up to sleep-disturbances [8,11,12]. According to some studies, these symptoms subside in $75-95 \%$ of patients within 2 weeks, while other research suggests, that a much larger percentage of patients exhibits persisting conditions [7,13,21]. "Post-Concussion Syndrome" is still widely used to describe lasting symptoms after TBI, but remains a problematic term due to multiple and partly conflicting definitions. Therefore, The American Medical Society for Sports Medicine proposes the term "Persistent Postconcussive Symptoms" (PPCS) to describe symptoms lasting for more than 2 weeks after TBI. PPCS should not be mistaken for CTE, which in contrast describes a chronic, neurodegenerative disorder that is associated with repetitive head trauma and is diagnosed neuropathologically. There is still a lot of controversy and discussion surrounding CTE. Incidence, specific causes and possible clinical manifestations of CTE are still lacking sufficient research [3,14,15,16,17].

Due to the broad range of possible neurological and psychological symptoms, psychiatric differential diagnosis of mTBI/PPCS can be challenging. Furthermore, pre-existing psychiatric conditions are a risk factor for more severe mTBI/PPCS symptoms [7,8]. A carefully taken patient history is therefore necessary to disentangle possible separate psychiatric diagnoses, such as depression, and treat them accordingly. Successful treatment of mTBI/PPCS often requires an interdisciplinary effort between sport physicians, neurologists, psychiatrists, physiotherapy and sometimes social workers. The first crucial step is an early side-line diagnosis right on the playing field in order to prevent further brain damage through continued sport participation. New guidelines advise - after a brief resting period of 24-48 hours - incremental increase in activity below the symptom-threshold [8,13]. The widespread practice of prescribing long-term rest might even lead to adverse outcomes [13]. In case of PPCS, psycho-education, psychotherapy and, if warranted, psychiatric medication can be also considered as a possible course of treatment. Some authors do suggest the use of antidepressants [18,19,20]. However, at present there is few, and even conflicting literature regarding the efficacy of medication and psychotherapy after mTBI [8]. Further possible treatment strategies can be improvement of sleep quality, physiotherapy, vision therapy and 
social/administrative support if necessary. This highlights the importance of an individual assessment of the patients' needs and of coordination between healthcare professionals in order to achieve optimal treatment for TBI/PPCS.

\section{Corresponding author}

Dr. med. Markus Deutschmann

Department of Psychiatry,

Psychotherapy and Psychosomatics

University Hospital of Psychiatry Zurich,

Zurich, Switzerland

markus.deutschmann@pukzh.ch

\section{References}

1. Martland HS. Punch drunk. Journal of the American Medical Association. 1928

2. Omalu BI, DeKosky ST, Minster RL, Kamboh MI, Hamilton RL, Wecht CH. Chronic traumatic encephalopathy in a National Football League player. Neurosurgery. 2005;57:128-34; discussion 128.

3. Smith DH, Johnson VE, Trojanowski JQ, Stewart W. Chronic traumatic encephalopathy - confusion and controversies. Nature Reviews Neurology. 2019;15:179-183.

4. Michael CD, Abbas R, Saksham G et al. Estimating the global incidence of traumatic brain injury. Journal of Neurosurgery JNS. 2018;130:1080-1097.

5. Binder S, Corrigan JD, Langlois JA. The public health approach to traumatic brain injury: an overview of CDC's research and programs. J Head Trauma Rehabil. 2005;20:189-195.

6. Schwarzbold M, Diaz A, Martins ET et al. Psychiatric disorders and traumatic brain injury. Neuropsychiatr Dis Treat. 2008;4:797-816.

7. Mayer AR, Quinn DK, Master CL. The spectrum of mild traumatic brain injury: A review. Neurology. 2017;89:623-632.

8. Polinder S, Cnossen MC, Real RGL et al. A Multidimensional Approach to Post-concussion Symptoms in Mild Traumatic Brain Injury. Front Neurol. 2018;9:1113.

9. Vos PE, Alekseenko Y, Battistin L et al. Mild traumatic brain injury. Eur J Neurol. 2012;19:191-198.

10. McInnes K, Friesen CL, MacKenzie DE, Westwood DA, Boe SG. Mild Traumatic Brain Injury (mTBI) and chronic cognitive impairment: A scoping review. PLoS One. 2017;12:e0174847.

11. Harmon KG, Drezner J, Gammons M et al. American Medical Society for Sports Medicine position statement: concussion in sport. Clin J Sport Med. 2013;23:1-18.

12. Aubry M, Cantu R, Dvorak J et al. Summary and agreement statement of the First International Conference on Concussion in Sport, Vienna 2001. Recommendations for the improvement of safety and health of athletes who may suffer concussive injuries. Br J Sports Med. 2002;36:6-10.

13. Harmon KG, Clugston JR, Dec K et al. American Medical Society for Sports Medicine position statement on concussion in sport. Br J Sports Med. 2019;53:213-225.

14. Asken BM, Sullan MJ, DeKosky ST, Jaffee MS, Bauer RM. Research Gaps and Controversies in Chronic Traumatic Encephalopathy: A Review. JAMA Neurol. 2017;74:1255-1262.

15. Manley G, Gardner AJ, Schneider KJ et al. A systematic review of potential long-term effects of sportrelated concussion. Br J Sports Med. 2017;51:969-977.

16. Montenigro PH, Baugh CM, Daneshvar DH et al. Clinical subtypes of chronic traumatic encephalopathy: literature review and proposed research diagnostic criteria for traumatic 
encephalopathy syndrome. Alzheimers Res Ther. 2014;6:68.

17. Noble JM, Hesdorffer DC. Sport-related concussions: a review of epidemiology, challenges in diagnosis, and potential risk factors. Neuropsychology review. 2013

18. Silverberg ND, Panenka WJ. Antidepressants for depression after concussion and traumatic brain injury are still best practice. BMC Psychiatry. 2019;19:100.

19. Barlow KM. Postconcussion Syndrome: A Review. Journal of Child Neurology J Child Neurol. 2014;31:57-67.

20. Register-Mihalik JK, Vander Vegt CB, Cools M, Carnerio K. Factors Associated with Sport-Related Postconcussion Headache and Opportunities for Treatment. Current Pain and Headache Reports. 2018;22:75.

21. McInnes K, Friesen CL, MacKenzie DE, Westwood DA, Boe SG. Mild Traumatic Brain Injury (mTBI) and chronic cognitive impairment: A scoping review. PLoS One. 2017;12:e0174847. 